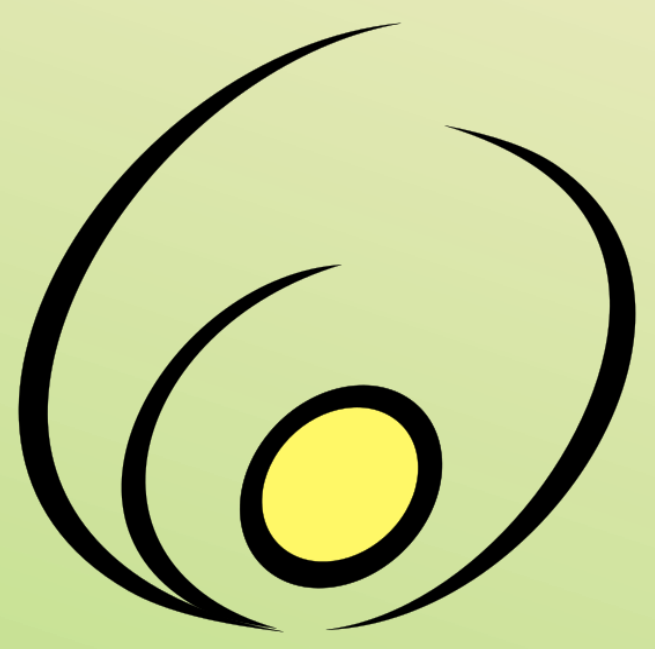

Fórum de

\section{Pró-Reitores}

\section{de Extensão}

\section{das Instituições}

Públicas de

\section{Educação Superior}

Brasileiras
Revista Brasileira de Extensão Universitária

v. 9, n. 2, p. 65-74 mai.- ago. 2018 e-ISSN 2358-0399

DOI: https://doi.org/10.24317/2358-0399.2018v9i2.7689

\title{
Construção de um biodigestor didático para a Estação Ciências do Parque Tecnológico de Itaipu
}

\author{
Flávio Ferreira Freitas ${ }^{1}$ \\ Andreia Cristina Furtado ${ }^{2}$ \\ Ana Letícia Yegros Cuevas ${ }^{3}$
}

Resumo: O presente trabalho apresenta a construção de um biodigestor didático para a produção de biogás a ser utilizado na Estação Ciências - Parque Tecnológico de Itaipu, destinado a alunos da educação básica. Os biodigestores produzem biogás mediante ação de bactérias anaeróbias que realizam a digestão de dejetos, tais como resíduos alimentícios e matéria orgânica em decomposição. Além do biogás, outro subproduto da digestão anaeróbia é o biofertilizante, usado na agricultura como substrato rico em nutrientes para plantas e vegetais. O objetivo final do projeto é obter um modelo de biodigestor padronizado, o qual não será usado para produção em larga escala, senão como modelo experimental de bancada, fomentando o conhecimento, a tecnologia e o ensino das energias renováveis em distintos ambientes. $\mathrm{O}$ foco desta pesquisa é promover a difusão do conhecimento, apresentando aos educadores uma forma de educação de ciências de forma simples, didática, visual e experimentada. A educação básica em ciências, especificamente o ensino de formas alternativas de produção de energia, constitui-se uma vertente de suma importância na popularização de ciências, na aprendizagem dinâmica, na conscientização da importância das energias renováveis e na redução do impacto ambiental causado pelos indivíduos no meio ambiente. Além do estudo, foi elaborado um modelo didático de biodigestor e uma cartilha didática para alunos da educação básica de modo a expandir e dinamizar o conhecimento a respeito de fontes alternativas de energia, neste caso, o biogás.

Palavras-chave: Pedagógico, Ensino-Aprendizagem, Biodigestão, Reator Batelada

Content shared under Creative Commons Attribution 4.0 Licence CC-BY

\footnotetext{
1 Pesquisador, Graduado em Engenharia de Energia, Grupo de Excelência em Geração Termoelétrica e Distribuída - NEST/IEM UNIFEI, Universidade Federal de Itajubá, Av. BPS 1303, C. P. 50, Itajubá, MG, CEP 37.500-903, (Brasil)+55 35 991050377. flaviofereirafreitas@gmail.com (autor para correspondência)

2 Docente da Universidade Federal da Integração Latino Americana - UNILA, Foz do Iguaçu, Brasil. Dra. em Engenharia Química, Brasil. andreiaf26@yahoo.com.br

3 Pesquisadora, Graduada em Arquitetura e Urbanismo, Universidade Federal da Integração Latino Americana - UNILA, Foz do Iguaçu, Paraná, Brasil. cuevasana5514@gmail.com
} 


\title{
Construction of a didactic biodigester for the Science Station of Itaipu Technological Park
}

\begin{abstract}
The present work describes the construction of a didactic biodigester for the production of biogas to be used at the Science Station - Itaipu Technological Park, destined for primary education students. The biodigesters produce biogas employing anaerobic bacteria that perform the digestion of waste, such as food waste, decomposed organic matter, among others. In addition to biogas, another by-product of anaerobic digestion is the biofertilizer, used in agriculture as a nutrient-rich substrate for plants and vegetables. The final objective of the project is to obtain a standardized biodigester model, which will not be used for large-scale production, but rather as an experimental bench model, fostering the knowledge, technology, and teaching of renewable energies in different environments. The focus of this research is to promote the knowledge diffusion, presenting to educators a form of science education in a simple, didactic, visual and experienced way. The primary science education, precisely the teaching of alternative forms of energy production, constitutes a crucial aspect in the popularization of science, in dynamic learning, looking for the awareness of the importance of renewable energies and in reducing the environmental impact caused by individuals in the environment. In addition to the study, a didactic model of biodigester was elaborated, and a didactic primer was developed for students of primary education in order to expand and streamline knowledge about alternative sources of energy, in this case, biogas.
\end{abstract}

Keywords: Pedagogical, Teaching-Learning, Biodigestion, Batch Reactor

\section{Construcción de un biodigestor didáctico para la Estación Ciencias del Parque Tecnológico de}

Itaipú

Resumen: El presente trabajo presenta la construcción de un biodigestor didáctico para la producción de biogás a ser utilizado en la Estación de Ciencias - Parque Tecnológico de Itaipú, destinado a alumnos de la educación básica. Los biodigestores producen biogás mediante acción de bacterias anaerobias que realizan la digestión de desechos, tales como, residuos alimenticios, materia orgánica descompuesta, etc. Además del biogás, otro subproducto de la digestión anaerobia es el biofertilizante, utilizado en la agricultura como sustrato rico en nutrientes para plantas y vegetales. El objetivo final del proyecto es obtener un modelo de biodigestor estandarizado, el cual no será usado para producción a gran escala, sino, como modelo experimental de bancada, fomentando el conocimiento, la tecnología y la enseñanza de las energías renovables en los distintos ambientes. El foco de esta investigación es promover la difusión del conocimiento, presentando a los educadores una forma de educación de ciencias de forma sencilla, didáctica, visual y experimentada. La educación básica en las ciencias, específicamente trabajar con la enseñanza de formas alternativas de producción de energía se constituye una vertiente de suma importancia en la popularización de las ciencias, el aprendizaje dinámico y la concientización de la importancia de las energías renovables y la reducción del impacto ambiental causado por los individuos en el medio ambiente. Además del estudio, se elaboró un modelo didáctico de biodigestor y una cartilla didáctica para alumnos de la educación básica para expandir y dinamizar el conocimiento acerca de fuentes alternativas de energía, en este caso, el biogás.

Palabras-clave: Pedagógico, Enseñanza-Aprendizaje, Digestión, Rectificador

\section{Introdução}

A energia proveniente da biomassa vem se destacando cada vez mais no âmbito industrial e também no rural. Atualmente, a maior parte da energia gerada da biomassa é resultado da queima direta de matéria orgânica em usinas termelétricas (ANEEL, 2008). O biogás, produzido a partir da digestão anaeróbia, é considerado um processo renovável, limpo, e permite reutilizar a biomassa in natura para gerar energia. Além do gás gerado no processo, tem-se como subproduto o biofertilizante, que pode ser utilizado na agricultura como insumo natural.

Atualmente existem várias tecnologias para o tratamento de dejetos e geração de energia. Entretanto, uma opção que apresenta maior facilidade de implementação e viabilidade, consiste na tecnologia de biodigestores anaeróbicos. Os biodigestores operam através de um sistema natural que utiliza a digestão anaeróbica das bactérias para produzir biogás e biofertilizante a partir de resíduos orgânicos.

Observa-se um acentuado crescimento no uso do biogás e do biofertilizante pelas famílias de zonas rurais, principalmente para suprir suas necessidades energéticas, onde o biogás é utilizado para aquecimento, iluminação, ou até mesmo em motores para gerar eletricidade, e o biofertilizante é usado para adubar o solo (VIEIRA et al., 2016).

De acordo com Bley Junior et al. (2009), o aproveitamento do biogás para geração de energia térmica e elétrica a partir da biomassa residual é um fator de grande importância para a descentralização da geração 
de energia e renda. Assim, há um forte impacto na economia local causada pelo desenvolvimento energético devido à produção de energia através do biogás. A geração de energia deve ser medida em quilowatt hora, qualidade ambiental e desenvolvimento microeconômico local. Através da geração de energia a partir de fontes limpas há ganhos indiretos como redução do conteúdo orgânico e do seu potencial poluente, redução da matéria descartada e depositada no ambiente, redução da emissão de gases poluentes e promove ainda a fixação da população nas comunidades.

A carga orgânica proveniente da geração de dejetos animais provocam passivos ambientais, tanto no que diz respeito à emissão de gases poluentes para a atmosfera, como a contaminação do solo (KUCZMAN et al., 2011). Logo, a produção de biogás é um modo de reaproveitamento dos dejetos que podem contribuir de forma positiva, nos aspectos socioeconômico e ambiental, fazendo uso de toda matéria gerada dentro das próprias residências para a produção de gás combustível.

O objetivo principal do projeto está na popularização das ciências, através da dinamização de formas alternativas de produção de energia limpa e sustentável. Desta forma, construiu-se em parceria com a Estação Ciências ${ }^{1}$ um protótipo de um biodigestor em escala de bancada para demonstrar essa forma alternativa de transformação de energia.

Além disto, foi desenvolvida também uma cartilha de simples entendimento, visando a facilitação do processo de ensino-aprendizagem das crianças a partir de uma história didática e ilustrativa.

Segundo a Lei de Diretrizes e Bases da Educação Nacional (LDB 9.394/96), em seu artigo $3^{\circ}$, inciso I, um dos princípios do ensino é garantir a igualdade de condições para o acesso e permanência na escola.

De acordo com Ianesko et al. (2017), uma maneira de garantir a permanência do aluno na escola e permitir a continuidade de seus estudos está na construção de formas de aprendizado que deem o impulso necessário para que o aluno adquira o conhecimento de modo satisfatório. Isto pode ser feito com a elaboração de cartilhas. Desta maneira, a cartilha pretende promover a divulgação da ciência, principalmente no que diz respeito a uma forma alternativa de produção de energia através de biodigestores.

\section{Referencial Teórico}

De acordo com Zuanon e Silva (2007), atualmente já existem à disposição da educação diversas estratégias de ensino que podem desencadear um melhor aproveitamento no aprendizado do aluno. Estas novas atividades permitem que o aluno possa interagir de forma mais efetiva saindo do ambiente teórico abordado pelo professor em sala de aula, e a partir de livros didáticos.

Desta maneira, o aluno deixa de ter uma postura neutra para, de forma crítica, abordar os novos conhecimentos, podendo ele discordar e discutir o que lhe é ensinado, interagindo não somente como aluno, mas também como pesquisador.

A escola possui um papel de destaque na formação crítica do aluno, e isto faz da escola um ambiente que deve ser multidisciplinar. A educação que prepara o aluno para o futuro deve ser problematizada e abordada criticamente, possibilitando a construção de novos conhecimentos. Esta preparação não deve ser linear e deve abordar distintas estratégias e métodos para o melhor desempenho do aluno no processo de ensino aprendizagem.

Um ambiente pouco inovador traz insatisfação e desmotivação, gerando um bloqueio na aprendizagem ou mesmo o êxodo de alunos das escolas. Neste contexto faz-se necessárias aulas práticas relacionadas aos conteúdos teóricos no ensino, com o objetivo principal de atrair a atenção dos alunos e impedir que o ambiente escolar se torne monótono, cansativo e de enfado (ANDRADE; MASSABNI, 2011).

Com isto, uma abordagem prática no ambiente escolar não serve apenas para romper as barreiras tradicionais da metodologia de ensino, mas também como forma de contribuir para o desenvolvimento científico e tecnológico do país (MARANDINO et al., 2009).

De acordo com Gomes et al. (2007), o ato de ler implica sempre no pensamento crítico cultural de ler e interpretar, reescrevendo o que foi lido. Desta maneira, a elaboração de novos materiais que sejam de fácil acesso, de simples compreensão, e que tornem o ensino menos retórico e dogmático, tem crescido massivamente no meio acadêmico.

Outro fator notório e que deve ser destacado consiste na interação entre a universidade e o ambiente escolar, sendo este, um dos pilares da extensão universitária. Esta interação cria no aluno novas perspectivas, e faz com que o sonho de estudar em uma universidade não seja apenas para os mais abastados social e economicamente.

O processo de ensino-aprendizagem, como já visto na história, não é linear e muito menos contínuo. Desta forma, a propiciação das práticas nos ambientes escolares permite ao aluno rever a partir de outras perspectivas o conteúdo teórico abordado em sala de aula facilitando o completo entendimento do tema. Assim, o aluno pode relacionar as informações, criar suas próprias conclusões e o professor pode retomar o tema já abordado a partir de um novo ângulo (LEITE et al., 2005).

O projeto possui a função de levar à escola, por meio de aulas práticas, a disseminação do conteúdo de ciências relativo às formas alternativas de produção de energia. Uma das importantes estratégias no ensino de ciências é a realização de aulas práticas em laboratórios ou mesmo a partir do desenvolvimento de materiais didáticos que contribuam para a concretização do conteúdo.

O biogás apresenta-se como um tema científico que possui um vasto campo de estudo sendo imprescindível que os alunos, dentro do ambiente escolar, tenham contato com as formas alternativas de produção de energia. 
O biogás gerado por meio da degradação de resíduos orgânicos em condições anaeróbicas é basicamente constituído de metano $\left(\mathrm{CH}_{4}\right)$. Historicamente, os biodigestores foram desenvolvidos na Índia, país que, já em 1970, possuía em torno de 2.500 instalações em uso, destinadas para a produção de gás e também de adubo (MASCARÓ, 2010).

A intensificação do uso do biogás ocorreu particularmente durante a Segunda Guerra Mundial na Alemanha e, com o tempo, em toda a Europa, devido à escassez de recursos energéticos.

De acordo com Lagrange (1979), a temperatura ideal de fermentação para a produção de adubos fica entre 30 e $35^{\circ} \mathrm{C}$. Porém, a temperaturas mais elevadas, em torno de $60^{\circ} \mathrm{C}$, ocorrem fermentações mais rápidas e eficientes, favorecendo as bactérias. No entanto, em temperaturas abaixo de $15^{\circ} \mathrm{C}$ e acima de $70^{\circ} \mathrm{C}$, o processo cessa totalmente.

A temperatura normal de operação das bactérias fermentativas oscila entre 30 e $60^{\circ} \mathrm{C}$. Em regiões de climas frios são necessários, em muitos casos, o uso de isolantes térmicos nas câmaras ou mesmo a utilização de aquecedores para alcançar maiores níveis de produção, como se pode perceber através da Figura 1.

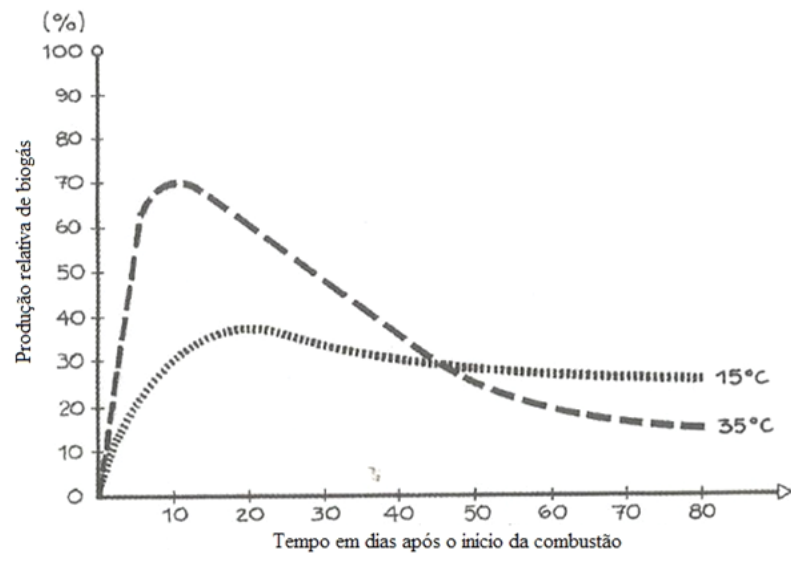

Figura 1. Variação da produção de gás em função da temperatura. Fonte: Mascaró (2010).

O gás produzido pela decomposição anaeróbia possui basicamente de $55 \%$ - $70 \%$ de metano $\left(\mathrm{CH}_{4}\right), 25 \%$ a $45 \%$ de gás carbônico $\left(\mathrm{CO}_{2}\right)$ e pequenas quantidades de outros gases, tais como o ácido sulfídrico $\left(\mathrm{H}_{2} \mathrm{~S}\right)$ que, além de possuir um odor forte característico de ovo podre, possui um alto poder de corrosão (KARLSSON et al., 2014).

$\mathrm{O}$ poder calorífico do gás produzido varia de 5.200 a $6.700 \mathrm{kcal} / \mathrm{m}^{3}$, o que pode ser relativamente baixo, quando comparado ao gás natural $\left(9.600 \mathrm{kcal} / \mathrm{m}^{3}\right)$ ou GLP $\left(11.960 \mathrm{kcal} / \mathrm{m}^{3}\right)$, ou mais elevado quando comparado ao gás manufaturado de nafta $\left(4.750 \mathrm{kcal} / \mathrm{m}^{3}\right)$ (FRARE et al., 2009).

A produção de biogás depende da matéria orgânica inserida no biodigestor. Desta forma, sua natureza tem papel fundamental no que diz respeito à produção de gás, como mostrado na Tabela 1 .

Tabela 1. Estimativa da produção de biogás por biomassa. Fonte: Sganzerla, (1983). Adaptado por Colatto e Langer (2012).

\begin{tabular}{cc}
\hline $\begin{array}{c}\text { Origem da matéria } \\
\text { orgânica }\end{array}$ & $\begin{array}{c}\text { Produção de Gás } \\
\left(\mathbf{m}^{\mathbf{3}} \cdot \mathbf{k g}^{-\mathbf{1}}\right)\end{array}$ \\
\hline Suínos & 0,35 \\
\hline Aves & 0,43 \\
\hline Ovinos & 0,25 \\
\hline $\begin{array}{c}\text { Resíduos vacuns e } \\
\text { cavalares }\end{array}$ & 0,04 \\
\hline Resíduos humanos & 0,45 \\
\hline
\end{tabular}

Os biodigestores se classificam em duas categorias: de produção descontínua ou contínua. Os biodigestores intermitentes, também chamados à batelada ou descontínuos, são os mais simples e exigem, para sua operação basicamente um recipiente hermeticamente fechado para a digestão anaeróbia do substrato. Além disso, normalmente possui uma campânula na parte superior, que recolhe o gás produzido na matéria orgânica em decomposição.

O processo de produção do biogás não ocorre na mesma velocidade e proporcionalidade. Normalmente, após a primeira semana, a produção do gás alcança o limite máximo seguido da completa queda na atividade do processo, geralmente completando o ciclo em um período de 8 a 10 semanas. Para contornar tal situação e garantir a constante produção do gás, geralmente trabalha-se com sistemas de no mínimo 3 biodigestores em sistema de rodízio, como mostrado na Figura 2.

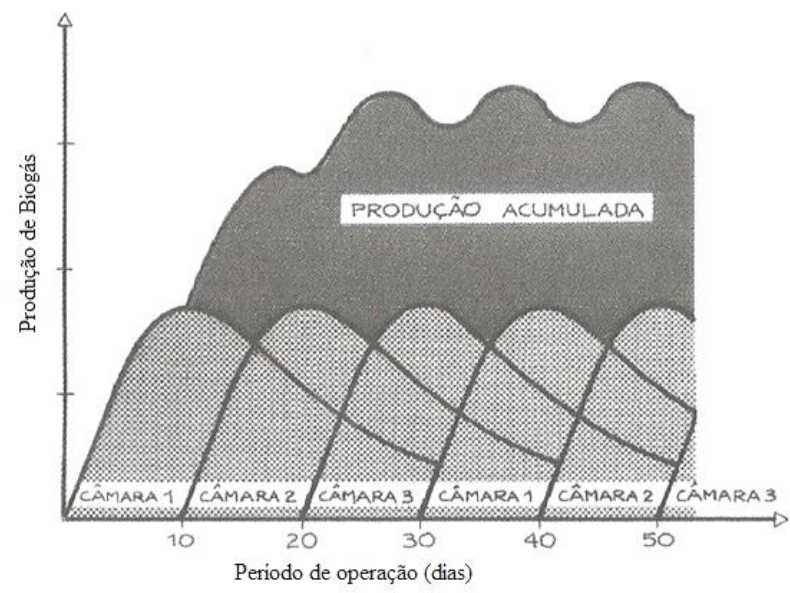

Figura 2. Produção de gás em uma instalação com três biodigestores descontínuos. Fonte: Mascaró (2010). 
Este tipo de unidade possui vida útil reduzida devido ao gás sulfídrico produzido na fermentação, que acelera a oxidação de materiais metálicos.

\section{Necessidades Energéticas}

O biogás pode ser utilizado em motores de automóveis com modificações na injeção e no carburador. A injeção deve sofrer alterações, pois a quantidade de ar necessária para uma combustão completa com gasolina é diferente de uma mistura de biogás com ar. Porém, o biogás deve passar por um processo de purificação para retirar parte do gás sulfídrico que pode converter-se em ácido sulfúrico e prejudicar os componentes do motor, devido ao alto poder de corrosão.

Por isto, o biogás produzido em pequena escala é mais utilizado para fins residenciais como, por exemplo, para aquecimento de água para banho, cozinha, lavanderia e uso em fogões e para cocção de alimentos. A quantidade de biogás necessária para cada aplicação descrita é expressa na Tabela 2. Cabe ressaltar que estes valores são médios e podem variar de acordo com o consumo pessoal residencial.

Tabela 2. Necessidades energéticas de biogás.

\begin{tabular}{|c|c|}
\hline Necessidade energética & $\begin{array}{c}\text { Consumo diário } \\
\text { de biogás } \\
\left(\mathrm{m}^{3} \operatorname{dia}^{-1} \text { pessoa }^{-1}\right)\end{array}$ \\
\hline Cocção de alimentos $\left(\mathrm{F}_{\mathrm{og}}\right)$ & 0,3 \\
\hline $\begin{array}{c}\text { Aquecimento de água para } \\
\text { banho }\left(\mathrm{AQ}_{\mathrm{ban}}\right)\end{array}$ & 0,2 \\
\hline $\begin{array}{l}\text { Aquecimento de água para } \\
\text { lavagem de utensílios de } \\
\text { cozinha }\left(\mathrm{AQ}_{\mathrm{coz}}\right)\end{array}$ & 0,1 \\
\hline $\begin{array}{c}\text { Aquecimento de água para } \\
\left.\text { lavagem de roupa (AQ } Q_{\text {lav_roupa }}\right)\end{array}$ & 0,3 \\
\hline
\end{tabular}

Fonte: Mascaró (2010).

\section{Dimensionamento dos Biodigestores}

O dimensionamento de biodigestores é realizado com base na necessidade diária do gás produzido.

As necessidades de gás diária $\left(\mathrm{N}_{\mathrm{g}}\right)$ são calculadas através da fórmula:

$\mathrm{N}_{\mathrm{g}}=\mathrm{n} *\left(\left(\mathrm{~F}_{\mathrm{og}}\right)+\left(\mathrm{AQ}_{\mathrm{ban}}\right)+\left(\mathrm{AQ}_{\mathrm{coz}}\right)+\left(\mathrm{AQ}_{\text {lav }_{\text {roupa }}}\right)\right)$

Sendo:

$\mathrm{N}_{\mathrm{g}}$ : Necessidade diária de gás $\left(\mathrm{m}^{3} / \mathrm{dia}\right)$;

n: número de residentes;

$\mathrm{F}_{\mathrm{og}}$ : Cocção de alimentos $\left(\mathrm{m}^{3} \mathrm{dia}^{-1}\right.$ pessoa $\left.^{-1}\right)$;
$\mathrm{AQ}_{\text {ban: }}$ Aquecimento de água para banho ( $\mathrm{m}^{3} /$ dia.pessoa); $\mathrm{AQ}_{\mathrm{coz}}$ : Aquecimento de água para lavagem de utensílios de cozinha $\left(\mathrm{m}^{3} /\right.$ dia.pessoa);

$\mathrm{AQ}_{\text {lav_roupa }}$ : Aquecimento de água para lavagem de roupa ( $\mathrm{m}^{3} /$ dia.pessoa).

O volume do biodigestor ou o volume do recipiente do digestor é calculado, considerando que a câmara deverá ser pelo menos, $30 \%$ maior do que o volume ocupado com o lodo em fermentação.

Desta forma, a carga mássica $\left(\mathrm{m}_{\text {bio }}\right)$ do biodigestor será calculado da seguinte forma:

$$
\mathrm{m}_{\text {bio }}=\left(m_{\text {org }_{\text {total }}} *\left(1+\frac{p_{a}}{100}\right) * t_{\text {ret }}\right)(k g)
$$

Onde:

$\mathrm{m}_{\text {bio }}$ : massa total do biodigestor $(\mathrm{kg})$;

$m_{\text {org total }}$ : massa de resíduo orgânico total $(\mathrm{kg})$;

$p_{a}$ : proporção de água que se necessita acrescentar (\%);

$t_{r e t}$ : tempo de retenção da matéria orgânica (dias).

Normalmente, a proporção de água é função da matéria orgânica utilizada como substrato.

A partir da massa total do biodigestor pode-se determinar o volume do biodigestor $(\mathrm{V})$. Considerando a densidade do substrato como aproximadamente a densidade da água a $25^{\circ} \mathrm{C}\left(1000 \mathrm{~kg} / \mathrm{m}^{3}\right)$.

$$
V=\left(1,3 *\left(\frac{\mathrm{m}_{\text {bio }}(\mathrm{kg})}{1000\left(\frac{\mathrm{kg}}{\mathrm{m}^{3}}\right)}\right)\right)
$$

Onde:

$\mathrm{m}_{\mathrm{bio}}$ : massa total do biodigestor $(\mathrm{kg})$; $\mathrm{V}$ : volume do biodigestor $\left(\mathrm{m}^{3}\right)$.

\section{Modelo Teórico}

Os biodigestores são câmaras hermeticamente fechadas onde há um processo de fermentação anaeróbia a partir de bactérias que se alimentam de matéria orgânica diluída em água, e apresentam como produtos o biofertilizante e o biogás. A concentração do gás produzido pelas bactérias depende de vários parâmetros como: $\mathrm{pH}$, temperatura, tempo de retenção, relação carbono/nitrogênio, disponibilidade de oxigênio e principalmente a composição da matéria orgânica (DEGANUTTI et al., 2002).

O biodigestor tipo batelada, em particular, é bastante utilizado devido à sua simplicidade de construção e operação.

Nestes biodigestores, a alimentação ocorre de uma só vez, mantendo a digestão por um certo período de tempo. Logo após a produção do gás, o material é descarregado e nova carga de matéria orgânica é introduzida no reator. 
Este modelo é utilizado com maior frequência quando a disponibilidade de matéria orgânica é intermitente, como ocorre por exemplo, em granjas avícolas de corte, ou quando é pequena a quantidade diária de gás necessária (DEGANUTTI et al., 2002).

\section{Análise Dimensional do Biodigestor}

Segundo Deganutti et al. (2002), o biodigestor modelo batelada é formado basicamente por um corpo cilíndrico, um gasômetro flutuante e uma estrutura para guia do gasômetro, como mostrado na Figura 3.

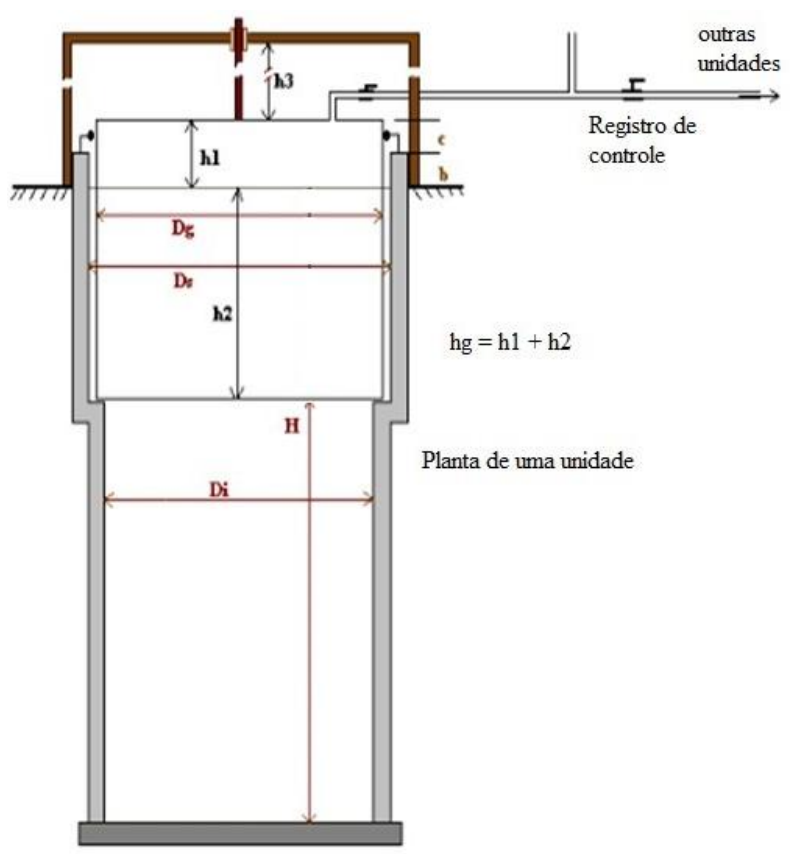

Figura 3. Biodigestor modelo batelada. Fonte: Frigo et al. (2015).

Onde:

Di é o diâmetro interno do biodigestor (m);

Ds é o diâmetro interno da parede superior (m);

Dg é o diâmetro do gasômetro (m);

H é a altura do nível do substrato (m);

$\mathrm{h}_{1}$ é a altura ociosa do gasômetro (m);

$\mathrm{h}_{2}$ é a altura útil do gasômetro $(\mathrm{m})$;

$\mathrm{h}_{3}$ é a altura útil para deslocamento do gasômetro $(\mathrm{m})$;

$\mathrm{h}_{\mathrm{g}}$ é a altura do gargalo, definida através da soma algébrica de $\mathrm{h}_{1}$ e $\mathrm{h}_{2}(\mathrm{~m})$;

b é a altura da parede do biodigestor acima do nível do substrato $(\mathrm{m})$;

c é a altura do gasômetro acima da parede do biodigestor (m).

Devido à simplicidade de projeto, operação e manutenção, o biodigestor modelo batelada foi escolhido para atender à proposição de ensino na educação básica. Para o projeto do reator foram selecionados materiais recicláveis, visando reduzir o custo de projeto e permitir a difusão do conhecimento.
O biodigestor foi construído utilizando um galão de 20 litros, como corpo do reator, e suas dimensões foram utilizadas como dados de entrada. A partir dos dados do reator, foi então realizado o cálculo da matéria prima necessária para a fermentação anaeróbia.

\section{Materiais e Método}

\section{Biodigestor didático}

Para a montagem do biodigestor em escala de bancada, prospectaram-se materiais recicláveis, uma vez que o foco principal do projeto está na disseminação do ensino em ciências.

Os materiais usados na construção do biodigestor foram:

- um galão de água de 20 litros vazio, para o biodigestor;

- uma câmara de pneu vazia, para o armazenamento de biogás;

- dois metros de tubulação de plástico maleável de diâmetro $6 \mathrm{~mm}$;

- um T de diâmetro 6 mm;

- uma válvula com registro de diâmetro $6 \mathrm{~mm}$;

- um metro de tubo PVC de diâmetro $20 \mathrm{~mm}$;

- duas tampas de PVC de diâmetro $20 \mathrm{~mm}$.

Para garantir o início do processo do biodigestor construído, conforme pode-se observar na Figura 4, é recomendável que a primeira carga de alimentação seja feita com dejeto bovino ou suíno, e também é necessário se certificar que a tubulação de saída esteja fechada com a tampa.

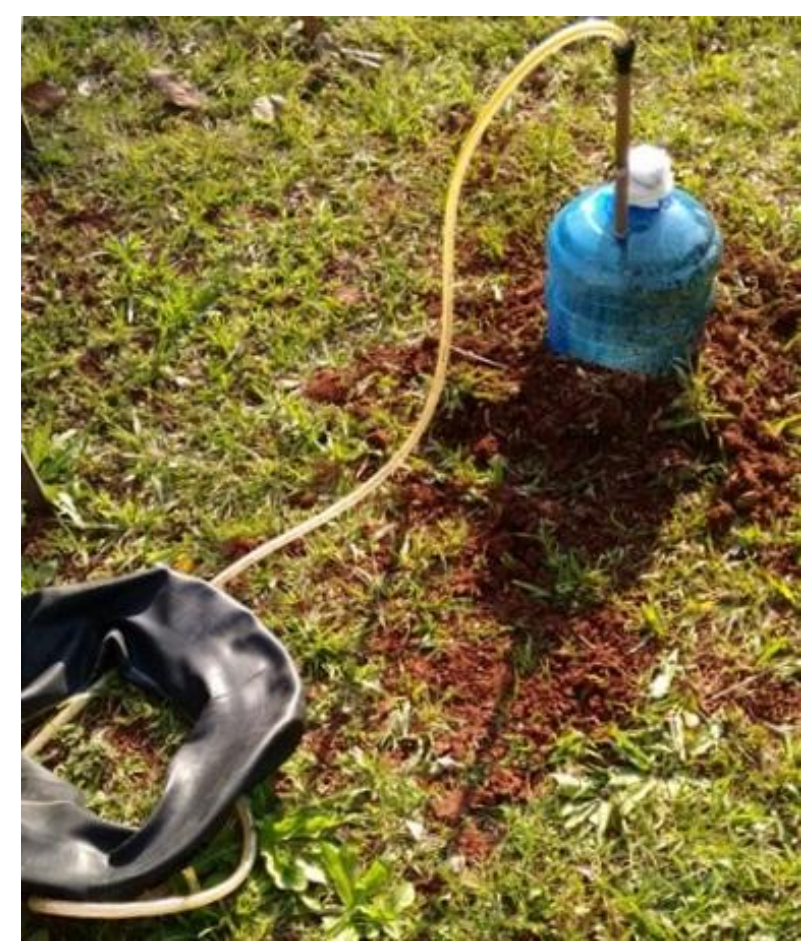

Figura 4. Biodigestor a batelada construído no projeto. Fonte: Elaboração própria. 
Nas próximas alimentações de substrato no biodigestor o tubo de saída deve estar aberto, sem a tampa, para permitir a saída da matéria orgânica já digerida. O material retirado do biodigestor pode ser utilizado como biofertilizante para adubar plantas.

\section{Material didático educativo (cartilha)}

Para a elaboração da cartilha foi realizada revisão bibliográfica sobre o funcionamento de biodigestores, bem como usos e aplicações. A cartilha não pretende esgotar o assunto, mas oferecer um panorama geral de uma forma alternativa de produção de energia através de biodigestores alimentados por resíduos animais/vegetais. No Paraná, como exemplificado na cartilha "Desafios de Dona Charmosa na Fazenda Futuro", existem em funcionamento, distintos locais de produção de energia elétrica provenientes do aproveitamento de resíduos para a produção de biogás.

O objetivo principal da cartilha é transmitir para as crianças de forma didática e simples uma nova forma de produção de energia.

Tendo este objetivo em vista, definiram-se os temas que deveriam ser abordados na cartilha: produção alternativa de energia a partir de biodigestores, utilização de dejetos para produção de energia, outras formas de obtenção de renda a partir de animais, funcionamento de um biodigestor, produtos resultantes da fermentação anaeróbia, usos e aplicações do biofertilizante e do biogás e uma breve inserção do tema do aquecimento global na educação ambiental de crianças.

Em seguida, buscou-se desenvolver um diálogo e um enredo para a história, dividindo em cenas e ambientes que fomentem a busca por informações, juntamente com a elaboração de imagens que fundamentem as mensagens. Por fim, realizou-se a validação da cartilha pela equipe pedagógica da Estação Ciências, para uma ampla revisão dos pontos de melhoria na elaboração da cartilha.

Foram elaboradas duas cartilhas, uma cartilha em preto e branco e outra com imagens coloridas que objetivam atrair a atenção das crianças. A Figura 5 apresenta uma das cenas da cartilha sem e com a colorização.

Esta cena faz menção à cena em que a vaca (Dona Charmosa), apesar de viver feliz em uma fazenda, acreditava que depois de algum tempo seria sacrificada.

\section{Análise dos Resultados}

\section{Análise Estrutural}

A quantificação da matéria orgânica que é alimentada no biodigestor foi determinada com base nas dimensões do reator, apresentadas na Tabela 3.

A altura do nível de substrato $(\mathrm{H})$ pode ser calculada a partir da equação:

$$
H=H_{t}-h_{1}-h_{2}-h_{3} \quad(m)
$$

Na qual:

H é a altura do nível do substrato (m);

$\mathrm{H}_{\mathrm{t}}$ é a altura total do biodigestor desde sua base;

$\mathrm{h}_{1}$ é a altura ociosa do gasômetro (m);

$\mathrm{h}_{2}$ é a altura útil do gasômetro $(\mathrm{m})$;

$\mathrm{h}_{3}$ é a altura útil para deslocamento do gasômetro (m).

A altura do gasômetro $\left(\mathrm{h}_{3}\right)$ se refere à altura livre para deslocamento da campânula.

A partir destes dados pode-se determinar o volume útil da unidade digestora a partir da equação abaixo (FLORENTINO, 2003; PORTES; FLORENTINO, 2006):

$$
\frac{\pi}{4} D^{2}\left(H+h_{2}\right) \geq V D
$$

Onde:

D é o diâmetro interno do biodigestor (m);

$\mathrm{H}$ é a altura do nível do substrato (m);

$\mathrm{h}_{2}$ é a altura útil do gasômetro (m);

VD é o volume útil da unidade digestora $\left(\mathrm{m}^{3)}\right.$.

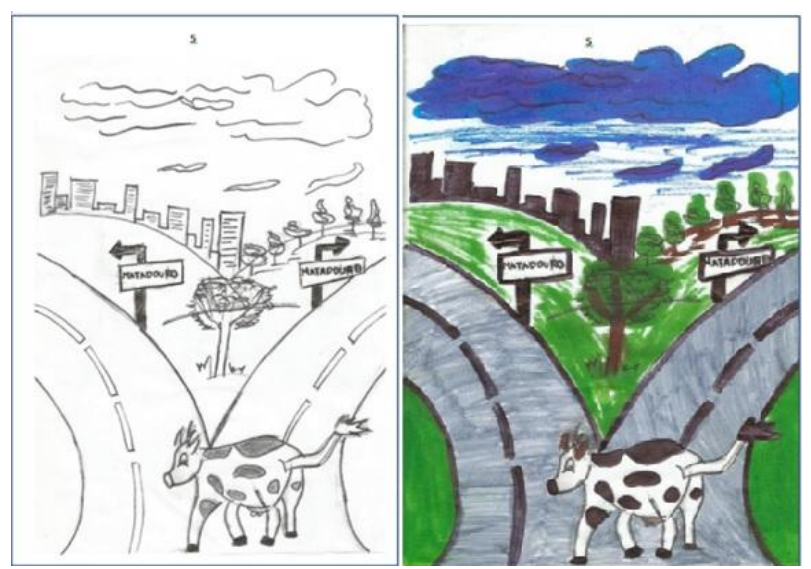

Figura 5. Página 5 da cartilha, Medo que assombrava Dona Charmosa. Fonte: Elaboração própria.

Tabela 3. Características estruturais do biodigestor.

\begin{tabular}{lc}
\hline Volume $(\mathrm{L})$ & 20 \\
\hline Peso $(\mathrm{g})$ & 833,5 \\
\hline Altura $\left(\mathrm{H}_{\mathrm{t}}\right)(\mathrm{cm})$ & 43,8 \\
\hline Altura do gargalo $\left(\mathrm{H}_{\mathrm{g}}=\mathrm{h}_{1}+\mathrm{h}_{2)}(\mathrm{cm})\right.$ & 2,3 \\
\hline Altura do gasômetro $\left(\mathrm{h}_{3}\right)(\mathrm{cm})$ & 8,7 \\
\hline Diâmetro "D” $(\mathrm{cm})(\mathrm{cm})$ & 27,6 \\
\hline Diâmetro int. bocal $(\mathrm{cm})$ & 4,0 \\
\hline Diâmetro ext. bocal "F" $(\mathrm{cm})$ & 5,2 \\
\hline
\end{tabular}

Fonte: Elaboração Própria. 
Devido à diluição, a densidade da mistura pode ser considerada como a da água. Desse modo pode-se calcular a massa de substrato a ser colocado no biodigestor, a partir da Equação:

$$
\rho=\frac{m(k g)}{V\left(m^{3}\right)}
$$

Em que:

$\rho$ é a densidade da mistura $\left(\mathrm{kg} / \mathrm{m}^{3}\right)$;

$\mathrm{m}$ é a massa de substrato do biodigestor $(\mathrm{kg})$;

$\mathrm{V}$ é o volume do biodigestor $\left(\mathrm{m}^{3}\right)$.

Cabe salientar que a massa encontrada não corresponde à quantidade de dejeto e sim à quantidade de substrato, sendo que este último leva em conta a quantidade de matéria de toda a mistura.

Para a determinação da produção diária de biogás, foi considerado o dejeto bovino como substrato, dada a facilidade do processo de biodigestão e à disponibilidade de dados referentes ao processo, disponíveis na literatura.

De acordo com a bibliografia utilizada, o esterco fresco deve ser diluído na proporção de 4 partes para 5 de água. Portanto, a quantidade de Biomassa Úmida (Bu) deve ser encontrada multiplicando a massa de substrato por $4 / 9$, conforme metodologia apresentada e recomendada Lucas Júnior et al. (2003).

Utilizando a tabela de conversão de biomassa para o dejeto bovino proposta por Sganzerla (1983), adaptado por Colatto e Langer (2012), pode-se inferir a produção total de biogás.

Esta produção se dá a partir da quantidade de dejeto inserido por batelada no biodigestor. Desta maneira, pode-se determinar a produção diária de biogás (Equação 7) sabendo que o tempo de retenção (TR) do substrato é de 20 dias (AMARAL, 2004). Desta forma, os dados calculados e medidos são apresentados na Tabela 4.

$$
B=\frac{P B}{T R} \quad\left(\frac{m^{3}}{d i a}\right)
$$

Onde:

B: produção diária de biogás $\left(\mathrm{m}^{3} / \mathrm{dia}\right)$;

PB: produção de biogás total $\left(\mathrm{m}^{3}\right)$;

TR: tempo de retenção (dias).

Salienta-se que a finalidade da construção deste biodigestor não visa obter gás para fins comerciais, senão, para fins acadêmicos, didáticos, de pesquisa e extensão.

A produção esperada deve se apresentar como a calculada anteriormente, ou seja, para cada $1,10 \mathrm{~kg}$ de matéria fresca adicionada, 0,0196 $\mathrm{m}^{3}$ de biogás serão produzidos, considerando a operação em regime permanente.
Tabela 4. Dados Técnicos da Produção de gás, através

\begin{tabular}{|c|c|}
\hline Altura do nível de substrato $(\mathrm{H})$ & $32,8 \mathrm{~cm}$ \\
\hline Massa de Substrato & $0,49 \mathrm{~kg}$ \\
\hline Biomassa úmida $(\mathrm{Bu})$ & $1,10 \mathrm{~kg}$ \\
\hline Produção de Biogás Total (PB) & $0,0196 \mathrm{~m}^{3}$ \\
\hline Tempo de Retenção do dejeto & 20 dias \\
\hline Produção Diária de Gás & $0,001 \mathrm{~m}^{3} / \mathrm{dia}$ \\
\hline
\end{tabular}
do biodigestor a batelada.

\section{Condições de operação do biodigestor}

Através do desenvolvimento do sistema didático de biodigestão espera-se criar um modelo que ofereça dados que possibilitem seu estudo em nível prático para os visitantes da Estação Ciências.

A temperatura é outro fator muito importante para o funcionamento do sistema. As bactérias que atuam na primeira fase da biodigestão anaeróbia se desenvolvem em temperaturas de $20^{\circ} \mathrm{C}$ a $25^{\circ} \mathrm{C}$, enquanto as bactérias que produzem o gás metano se multiplicam em temperaturas mais elevadas, de $35^{\circ} \mathrm{C}$.

Além disso, o biodigestor deve ser agitado no mínimo 2 vezes por semana. A agitação é importante para manter um contato total e permanente das bactérias com os dejetos, uniformizar a temperatura e as camadas que existem dentro do biodigestor. Além do que, a agitação também destrói microbolhas de gases formadas no interior da mistura e que aprisionam as bactérias, impedindo sua atuação na degradação dos dejetos e formação do biogás.

O biodigestor deve estar acondicionado, logo, para sua construção em Foz do Iguaçu (Paraná), não há necessidade de sistema de aquecimento ou refrigeração, já que se trata de uma região com variação térmica anual dentro dos parâmetros para o bom funcionamento do biodigestor. Uma maneira de reduzir a influência da amplitude térmica diária de Foz do Iguaçu, que pode ser elevada, é construir parte do biodigestor enterrado no solo, onde a oscilação de temperatura diária é menor, tanto no verão como no inverno.

Porém, cabe destacar neste caso que o local para sua instalação seja selecionado adequadamente, onde não haja sombra causada por árvores pela manhã ou tarde e tampouco raízes que venham a causar danos na estrutura do biodigestor. 


\section{Conclusões}

A metodologia utilizada foi reversa à metodologia que normalmente é realizada para o dimensionamento de um biodigestor. Normalmente para uma determinada demanda se estabelece o tamanho do biodigestor a ser construído. Neste caso, como não há intenção de produzir biogás em larga escala e sim demonstrar seu funcionamento a partir de um modelo experimental de bancada, escolheu-se primeiramente o biodigestor com materiais recicláveis e logo após definiu-se então a quantidade de matéria orgânica necessária para sua alimentação.

Após a produção do biogás, juntamente com a elaboração da cartilha, observou-se a importância do uso de experimentação para a melhoria do ensino-aprendizagem na internalização de conceitos. Além disto, a participação coletiva dos alunos em busca da produção de biogás através do biodigestor didático promove a interação social, base para a aprendizagem conjunta.

No Brasil, considerando que as usinas hidroelétricas constituem mais da metade da matriz elétrica nacional, os alunos tendem a concentrar suas pesquisas, estudos e conhecimentos nesta fonte energética. No entanto, existem diversas outras fontes que podem produzir energia, seja solar, eólica e inclusive a biomassa, fonte do biogás. Desta maneira, a elaboração da cartilha apresenta impacto social promovendo a disseminação de fontes alternativas de energia e popularização das ciências.

Além disto, a proposta deste trabalho contribui para o reaproveitamento da matéria orgânica e sua utilização na produção de energia. Esta simples ação atua como motor propulsor para a conscientização dos alunos quanto à importância do uso correto da energia, do reaproveitamento energético, e do descarte correto do lixo. Estas ações promovem a sustentabilidade por meio da redução dos impactos ambientais gerados pelo ser humano ao meio ambiente.

A partir deste artigo, pretende-se em trabalhos futuros ampliar o desenvolvimento de novos protótipos e modelos que produzam gás em maior escala e de melhor qualidade, como também, dinamizar e intensificar o ensino de ciências com esta forma alternativa de produção de energia, ainda pouco explanada em muitas regiões do Brasil.

Esta proposta consiste em um subsídio para a construção de outros biodigestores, de acordo com as necessidades sociais e econômicas em cada localidade.

\section{Agradecimentos}

À orientadora e supervisora do Trabalho de Conclusão de Curso: "Construção de um Biodigestor Didático para a Estação Ciências do Parque Tecnológico de Itaipu" que culminou na elaboração deste artigo e também na publicação de um livro didático denominado: Desafios de Dona Charmosa na Fazenda Futuro.
À Estação Ciências por colaborar com a elaboração do projeto. Ao Fabiano Nogueira pela gerência da Estação e ao suporte prestado e também sua equipe técnica pedagógica que muito contribuiu com a elaboração da cartilha.

Por fim, à universidade pelo conhecimento adquirido através dos professores e por permitir a elaboração de tais trabalhos que fomentem a educação de ciências, a pesquisa e inovação.

\section{Contribuições de cada autor}

F.F.F.: Mestrando e graduado em Engenharia de Energia, responsável pelo projeto, participou do planejamento, execução e confecção do manuscrito. A.C.F.: Prof ${ }^{a}$. Dr ${ }^{a}$. orientadora e supervisora do projeto, também participou na concepção do projeto, análise, correções e confecção do manuscrito. A. L. Y. C.: Graduada em Arquitetura e Urbanismo, participou da concepção e elaboração do projeto, principalmente no tocante à concepção pedagógica e artística da cartilha didática, um dos produtos do projeto. Participou também na construção científica do manuscrito, considerando as etapas de leitura e revisão.

\section{Notas}

1. A Estação Ciências é um espaço para popularizar, disseminar e fortalecer a cultura científica por meio de práticas investigativas para o ensino das ciências. Está localizada no Parque Tecnológico de Itaipu - PTI - na cidade de Foz do Iguaçu, Paraná.

\section{Referências}

AMARAL, C. M. C. Biodigestão anaeróbia de dejetos de bovinos leiteiros submetidos a diferentes tempos de retenção hidráulica. Ciência Rural, v. 34, n. 6, p. 1897 1902, 2004.

ANDRADE, M. L. F.; MASSABNI, V. G. O desenvolvimento de atividades práticas na escola: um desafio para os professores de ciências. Ciência \& Educação, v. 17, n. 4, p. 835-854, 2011.

ANEEL - Agência Nacional de Energia Elétrica. Atlas de Energia Elétrica do Brasil. 3. ed., Brasília: Aneel, 2008. 236p.

BLEY JUNIOR, C.; LIBÂNIO, J. C.; GALINKIN, M.; OLIVEIRA, M. M. Agroenergia da biomassa residual: perspectivas energéticas, socioeconômicas e ambientais. Foz do Iguaçu/Brasília: Technopolitik Editora, 2009.

COLATTO, L; LANGER, M. Biodigestor - resíduo sólido pecuário para produção de energia. Unoesc \& Ciência-ACET, v. 2, n. 2, p. 119- 128, 2012.

DEGANUTTI, R.; PALHACI, M. C. J. P.; ROSSI, M.; TAVARES, R.; SANTOS, C. Biodigestores rurais: 
modelos, indiano, chinês e batelada. In: ENCONTRO DE ENERGIA NO MEIO RURAL, 4, 2002, Bauru: Faculdade de Arquitetura, Artes e Comunicação. Anais... UNESP, 2002.

FLORENTINO, H. O. Mathematical tool to size rural digesters. Scientia Agricola, v. 60, n. 1, p. 185-190, 2003.

FRARE, L. M.; GIMENES, M. L.; PEREIRA, N. C. Processo para remoção de ácido sulfídrico de biogás. Engenharia Sanitária e Ambiental, v. 14, n. 2, p. 167$172,2009$.

FRIGO, K. D. A.; FEIDEN, A.; GALANT, N. B.; SANTOS, R. F.; MARI, A. G.; FRIGO, E. P. Biodigestores: seus modelos e aplicações. Acta Iguazu, v. 4, n. 1, p. 57-67, 2015.

GOMES, R. P. M.; TIZUKA, M. M.; OLIVEIRA, J. S.; BORGES, D. L. Abordagem educativa em Ciências da Terra no Parque Estadual de Ilhabela, Estado de São Paulo, por meio de caminhadas geológicas e uso de materiais didáticos. In: SIMPÓSIO DE PESQUISA EM ENSINO E HISTÓRIA DE CIÊNCIAS DA TERRA, 1 \& SIMPÓSIO NACIONAL SOBRE ENSINO DE GEOLOGIA NO BRASIL, 3, 2007, Campinas. Anais... São Paulo: UNICAMP, 2007.

IANESKO, F.; DE ANDRADE, C. K.; FELSNER, M. L.; ZATTA, L. Elaboração e aplicação de histórias em quadrinhos no ensino de Ciências. Experiências em Ensino de Ciências, v. 12, n. 5, p. 105-125, 2017.

KARLSSON, T.; KONRAD O.; LUMI, M.; SCHMEIER, N. P.; MARDER, M.; CASARIL, C. E.; KOCH, F. F.; PEDROSO, A. G. Manual Básico de Biogás. Lajeado: Ed. da UNIVATES, 2014.

KUCZMAN, O.; GOMES, S. D.; TAVARES, M. H. F.; TORRES, D. G. B.; ALCÂNTARA, M. S. Produção específica de biogás a partir de manipueira em reator de fase única. Engenharia Agrícola, v. 31, n. 1, p. 143-149, 2011.

LAGRANGE, B. Biométhane. Tome 2: Principes, Techniques, Utilizations. EDISUD/Energies alternatives, Aix en Provence. 1979.

LEITE, A. C. S.; SILVA, P.A. B.; VAZ, A. C. R. A importância das aulas práticas para alunos jovens e adultos: uma abordagem investigativa sobre a percepção dos alunos do PROEF II. Ensaio Pesquisa em Educação em Ciências, v. 7, n. 3, p. 166-181, 2005.

LUCAS JÚNIOR, J.; SOUZA, C. F.; LOPES, J. D. S. Construção e Operação de biodigestores. Jaboticabal: UNESP, 2003.

MARANDINO, M.; SELLES, S. E.; FERREIRA, M. S. Ensino de Biologia: histórias e práticas em diferentes espaços educativos. São Paulo: Cortez, 2009.

MASCARÓ, J. L. Sustentabilidade em Urbanizações de Pequeno Porte. Porto Alegre: Masquatro Editora, 2010.

PORTES, Z. A.; FLORENTINO, H. O. Aplicativo computacional para projetos e construções de biodigestores rurais. Energia na Agricultura, v. 21, n. 1, p. 118-138, 2006.

SGANZERLA, E. Biodigestor: uma solução. Porto Alegre: Agropecuária, 1983.

VIEIRA, M. T.; MIRANDA, D. H.; BASQUEROTTO, C. H. C. C. Utilização do subproduto proveniente da produção de biogás como fertilizante. Revista Conexão Eletrônica, v. 13, n. 1, 2016.

ZUANON, A. C. A.; SILVA, C. A. O biolhar contextualizado da Botânica fora do livro didático. Revista SBEnBio, n.1, p. 10-11, 2007.

\begin{tabular}{l} 
*** \\
\hline Como citar este artigo: \\
FREITAS, F. F.; FURTADO, A. C.; CUEVAS, A. L. Y. \\
CONSTRUÇÃ̃ DE UM BIODIGESTOR DIDÁTICO PARA \\
A ESTAÇÂO CIÊNCIAS DO PARQUE TECNOLÓGICO DE \\
ITAIPU. Revista Brasileira de Extensão Universitária, v. 9, \\
n. 2, p. 65-74, 2018. Disponível em: \\
https://periodicos.uffs.edu.br/index.php/RBEU/article/ \\
$\underline{\text { view/7689/pdf }>}$
\end{tabular}

